\title{
Performance analysis and dynamic test of single cylinder diesel engine Liankun Chi ${ }^{1, a}$, Lihua Wang ${ }^{1, b}$, Qi Wang ${ }^{2, c}$ \\ ${ }^{1}$ Mechanical and Electrical Engineering College, Kunming University of Science and Technology,kunming,China \\ 2 Dongan Automotive Engine Manufacturing Co., Ltd.., Ltd.,haerbin,China \\ a741584574@qq.com, bkmwanglihua@163.com, ${ }^{\mathrm{c}} 215637361 @ q q . c o m$
}

Keywords: diesel engine; performance parameter; working process calculation;

Abstract.Some optimization are applied on TBD620 diesel engines in order to enhance its power and reliability and reduce the manufacturing cost. For the study of engine parameters influence on its working process, and reduce the experiment cost, we developed 620 single cylinder machine in the process of improvement and optimization. And a series of performance test are applied on the single cylinder test machine.It is necessary and valuable for the performance parameters optimization of single cylinder test conducted on diesel engine to use the working process software to simulate and analysis the performance of the single-cylinder engine.

\section{Introduction}

Today diesel industry is facing serious challenges and can not escape the challenge, first, because the increasing depletion of oil resources caused by the energy crisis and reduce the energy consumption of the power plant is an urgent problem, more importantly, to defend our living natural environment. We must reduce diesel exhaust pollutants, therefore, governments have introduced a new law in high demand, and secondly, the market competition in terms of the power plant even more intense, the professional research work in today's challenge has become more difficult.

Various parameters of single-cylinder machines work index and single-cylinder engine is closely related to work and single-cylinder machine parameters and design parameters are closely related, such as single-cylinder machine cylinder diameter, stroke, speed, compression ratio. Subtle changes in single-cylinder machine body parameters such that the respective work of the diesel engine will produce great changes, causing major changes in the single-cylinder machine performance metrics. In today's electronic control technology continues to mature, a lot of engineering software for the design process has brought us convenience.

\section{The basic parameters of single cylinder machine}

Table 1.1 parameters of 620 single cylinder diesel engine

\begin{tabular}{cc}
\hline Parameter name (unit) & numerical value \\
\hline Bore / stroke $(\mathrm{mm} / \mathrm{mm})$ & $170 / 195$ \\
working process & Four stroke \\
Combustion mode & Direct injection \\
Cylinder volume $(\mathrm{L})$ & 4.43 \\
Compression ratio & $13.5: 1$ \\
Cooling mode & water-cooling \\
Calibration speed / power $(\mathrm{kW} / \mathrm{r} / \mathrm{min})$ & $160 / 1860$ \\
Fuel consumption rate $(\mathrm{g} / \mathrm{kW} \cdot \mathrm{h})$ & $205 \pm 5 \%$ \\
\hline
\end{tabular}


In the process of modeling a single-cylinder machine, the software needs of the general parameters set air-fuel ratio, flow coefficient, pressure, flow and temperature. Wherein, in the parameter setting gas distribution system, the intake of air-fuel ratio is set to infinity, the exhaust air-fuel ratio in accordance with customary setting. This pressure and temperature inside the state of the environment and stable operation of the diesel engine when. Flow coefficient is generally determined by the bell characteristics, as well as the tail end of the intake pipe to the mounting position of the pitch decisions.

The only line of the friction loss has a pressure loss calculations, geometry pipeline valves and other losses only in place to generate. Wherein the flow coefficient is the same or critical pressure when the flow and destructive than the real flow in Abigail.

Single-cylinder machine calculated using Woschni 1978 heat transfer model.

The remaining parameters, can go to the manual query, or measured according to the size of single-cylinder machine. The main input parameters are shown in Table 1.1620 single-cylinder diesel engine parameter table.

Using simulation model AVL BOOST established 1. 1 BOOST simulation model shown in Figure.

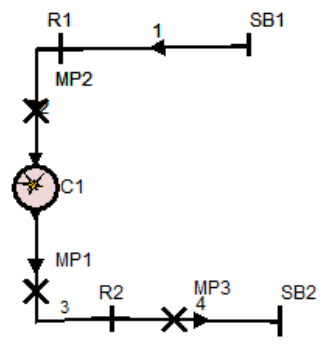

Fig. 1.1 simulation model of BOOST

In Figure 1.1: sb1 is the air intake system of the border, sb2 boundary vent system; $\mathrm{R} 1$ is constrained; $\mathrm{C} 1$ for the cylinder; MP1, MP2, MP3 measurement points.

\section{Validation of model}

The simulation model has been completed based on the single-cylinder machine TBD620 began a series of simulation analysis, the simulation results with experimental data TBD620V16 is done before such as the table shows, the effective power of the test is $160 \mathrm{~kW} 2.1$, simulation value of $160.39 \mathrm{~kW}$, the error is $0.02 \%$; effective fuel consumption rate test is $202 \mathrm{~g}$, simulation is $207.7857 \mathrm{~g}$, error is $2.8 \%$; the outbreak of the pressure test is $15.55 \mathrm{MPa}$, simulation analysis is $15.49 \mathrm{MPa}$, the error is $0.38 \%$ simulation analysis parameter differences results with actual experimental measurements within the allowable range, the proof model is correct, can be used for subsequent calculations.

Table 2.1 comparison of simulation data and test data

\begin{tabular}{ccccc}
\hline & $\begin{array}{c}\text { power } \\
(\mathrm{kW})\end{array}$ & $\begin{array}{c}\text { Fuel consumption } \\
\text { rate }(\mathrm{g} / \mathrm{kWh})\end{array}$ & $\begin{array}{c}\text { Detonation } \\
\text { pressure(MPa) }\end{array}$ & $\begin{array}{c}\text { Average effective } \\
\text { pressure }(\mathrm{MPa})\end{array}$ \\
\hline $\begin{array}{c}620 \mathrm{~V} 16 \\
\text { experimental data }\end{array}$ & 160 & 202 & 15.55 & 1.753 \\
$\begin{array}{c}\text { 620Simulation of } \\
\text { single cylinder } \\
\text { engine }\end{array}$ & 160.39 & 207.78 & 15.49 & 1.750 \\
\hline
\end{tabular}

620 single-cylinder machine simulation and 620V16 test measured cylinder pressure curve comparison shown in Fig. 2.1, according to the picture can see that the results of the stress analysis and experimental simulation was very close, very little difference. 


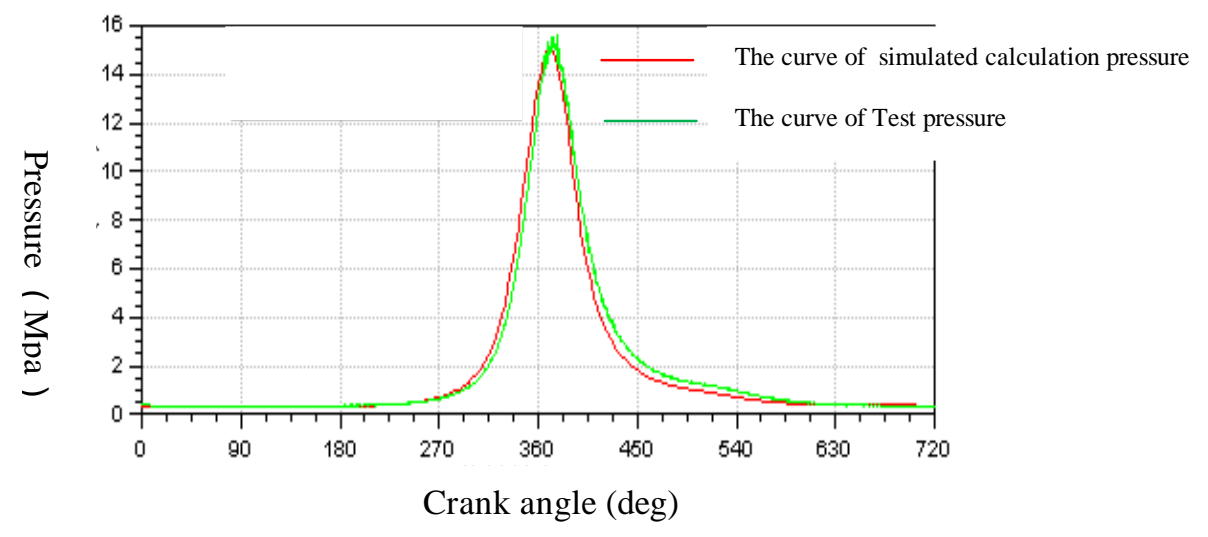

Fig. 2.1 comparison of simulation and experiment

Temperature and pressure curve in the cylinder of the engine shown in FIG2.2,2.3, can be analyzed, the maximum pressure within the cylinder is $15.4872 \mathrm{MPa}$, maximum temperature is $1691.37 \mathrm{~K}$. Maximum pressure within the cylinder is located on the dead point about $12^{\circ} \mathrm{CA}$ after the highest temperature inside the cylinder at the top dead center about $27^{\circ} \mathrm{CA}$ after about, it had a very good representation of fuel combustion, the combustion process is ideal. The simulation results of the rest of the pressure and temperature are related to the past not much different, and closer to the actual value.

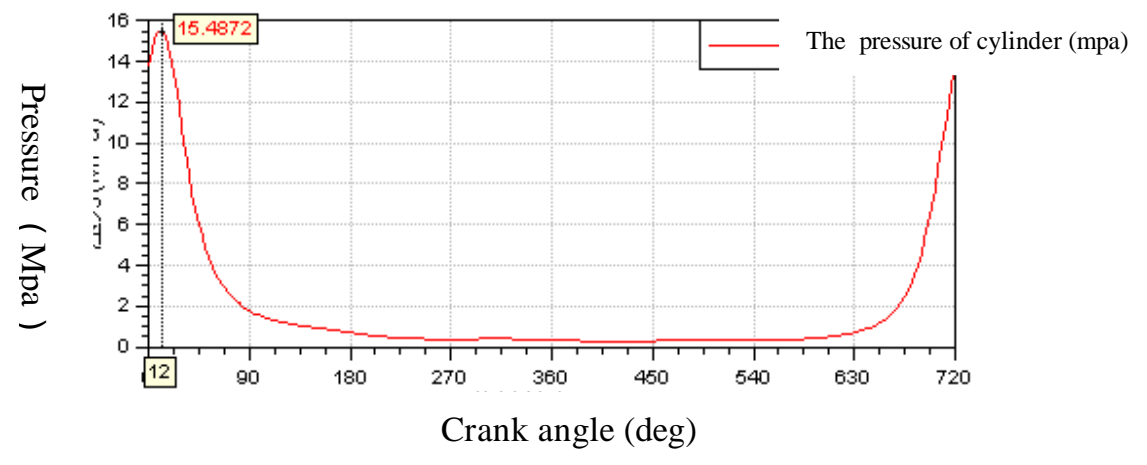

Fig. 2.2 cylinder pressure curve

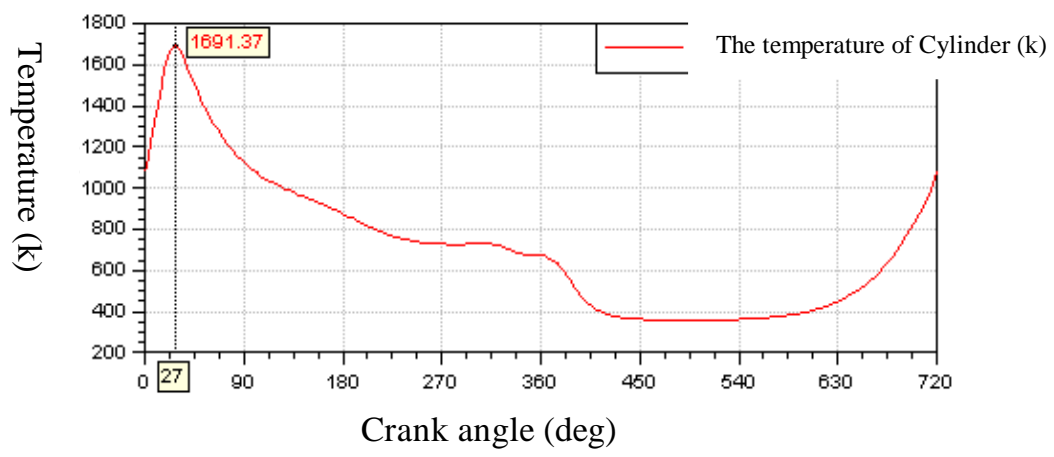

Fig. 2.3 cylinder temperature curve

For example, as shown in Figure 2.4 Pressure born from analysis, the ratio of positive and negative pressure raw Extreme is: 3.50381bar / deg and -3.84487bar / deg. Pressure student ratio curve is relatively normal, single-cylinder machine to alleviate the heat load and knock have some fuctions. 


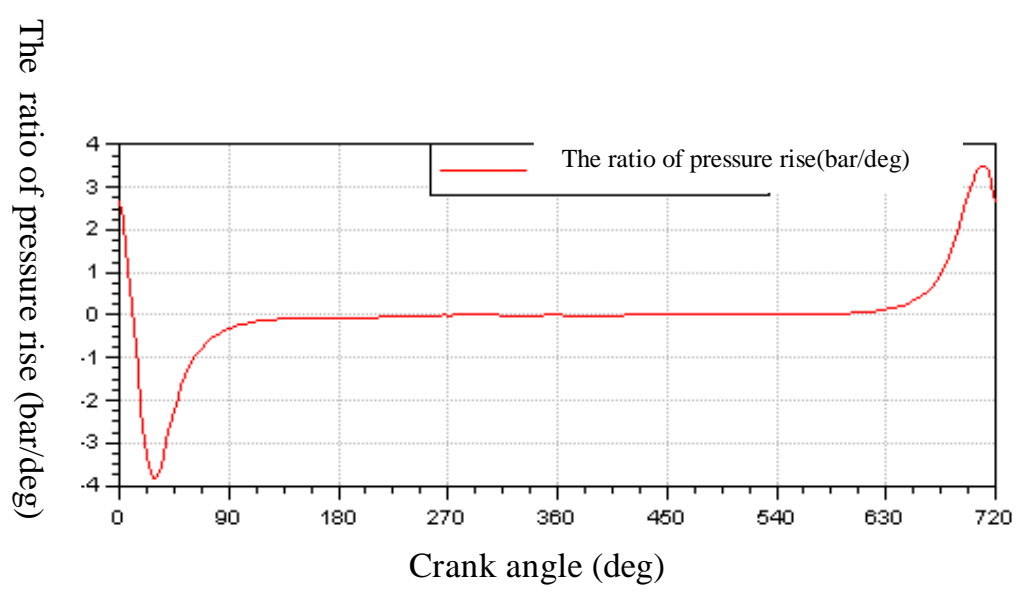

Fig. 2.4 curve of pressure rise

Simulation results show that the simulation data with the experimental data about the same, basically proved correct simulation model, the simulation results for later analysis plays an important role.

\section{Single cylinder engine test}

Through the establishment of single-cylinder diesel engine test platform 620, in accordance with the single-cylinder diesel engine performance test program complete the performance test, reaching 620 single-cylinder diesel engine performance. Pressure Transmitter: Range 2MPa, power 24V, output 4 $20 \mathrm{~mA}$, working temperature is $0{ }^{\circ} \mathrm{C} \sim 150^{\circ} \mathrm{C}$. Temperature sensor: Type Pt 100 , measuring range -100 $\stackrel{\circ}{ } \mathrm{C} \sim 200 \stackrel{\circ}{\circ} \mathrm{C}$.

Table 3.1 standard environment for testing

\begin{tabular}{cc}
\hline ambient temperature & $45^{\circ} \mathrm{C}$ \\
\hline atmospheric pressure & $100 \mathrm{kPa}$ \\
Circuit coolant temperature & $32^{\circ} \mathrm{C}$ \\
Atmospheric humidity & $60 \%$ \\
\hline
\end{tabular}

Boot 620 single-cylinder machine and various ancillary equipment operation, running after a period of time, found several phenomena: the oil return oil not free, low pressure fuel system and lubrication system pressure and oil pump sound, etc. For the below several circumstances, make reasonable solution .

Because of heavy oil viscosity, found that the oil from the cylinder machine back into the fuel tank is not smooth, through in a single cylinder machine return pipe road and oil pump inlet pipe valves and the installation is equivalent to the sump short circuit. After more lubricating oil into the body, open the valve, close the valve, directly by the oil pump oil absorption from the single cylinder engine oil pan .Low pressure fuel pump system and lubrication system pressure, the low pressure fuel pump and oil pump oil outlet of the bypass valve installation, by-pass line received at the inlet of the pump, by observing the pressure gauge readings to adjust the opening of the by-pass valve, with the increase of the opening of the by-pass valve, fuel system and lubrication system pressure drop down, then reached a reasonable range, at the same time, the oil pump of sound is also as the pressure drop down, and then solve it .

After a series of debugging, single-cylinder machine run smoothly, performance parameters without exception, fuel supply system, lubrication system and cooling water system and other parameters in a reasonable range. Fuel delivery system can be achieved by adjusting the pressure $0.5 \mathrm{MPa}$, smooth operation for oil pump without oil leakage phenomenon; Lubrication system can also adjust the pressure is $0.5 \mathrm{MPa}$, the oil pump operates smoothly, no lubricating oil leakage phenomenon; Cooling 
water temperature can reach $70{ }^{\circ} \mathrm{C}$, under the rated conditions and cooling water pump operates smoothly, no cooling water leakage phenomenon. The instrument display of each systems all normal, within a reasonable range, can be further studied.

\section{Performance test}

According to the performance test program to promote the characteristic test of single cylinder machine, promote the characteristic test table are shown in table 5.1.

Before the test, precision measurement of single cylinder diesel with the requirements of the important parts. In a single cylinder machine has not started, in turn open the power supply, low pressure fuel pump, oil pump, cooling water pump, run 5 minutes, the lubricating oil and cooling water flow within the cylinder machine, to prevent sudden start, between caused by the wear of the piston in the cylinder, to start to prepare for single cylinder machine. Check the single cylinder machine, bench, and the workings of the pipeline, the phenomenon such as leaks. All the accessory system to work properly, start the single-cylinder engine experiment.

\section{Test result}

620 single-cylinder engine performance experiment, single cylinder machine run smoothly, performance parameters without exception, fuel supply system, lubrication system other parameters in a reasonable range. The instrument display of each systems all normal, within a reasonable range, 620 single-cylinder engine test-bed carry is proved to be reasonable. Test before and after the parts precision measurement, which indicates that a 620 single-cylinder diesel engine developed by the overall structure and reliable in performance, abrasion of parts and components conform to the requirements, the technology is stable, the whole machine reliability meet the requirements. 
Table 4.1 propulsion performance test

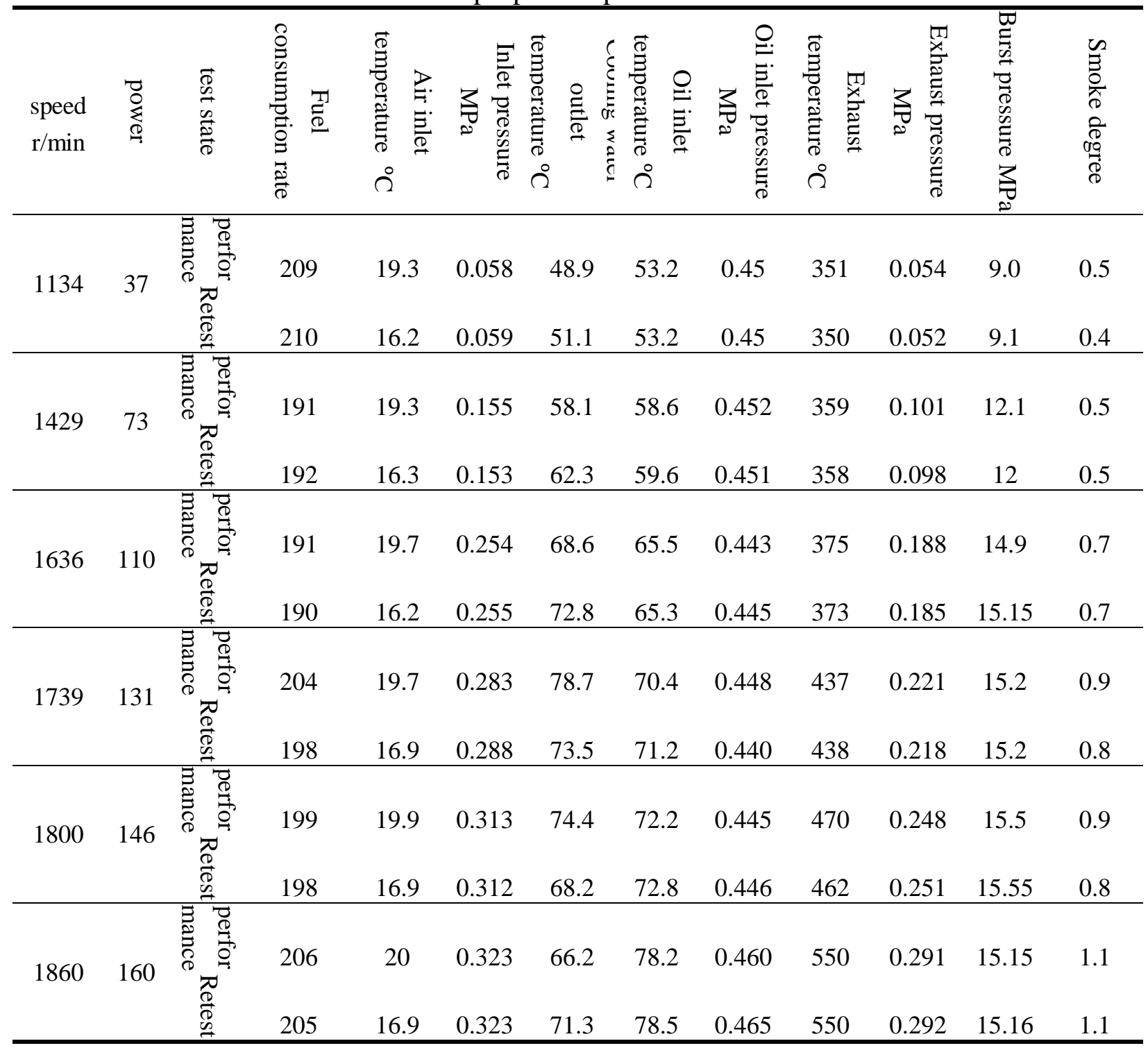

After the test, according to the existing test data under the rated conditions, the test results of TBD620 single cylinder diesel engine with done before TBD620V16 test data for such as shown in table 4.2, the effective TBD620V16 specific fuel consumption test value is $202 \mathrm{~g}$, TBD620 effective single-cylinder engine fuel consumption rate is $206 \mathrm{~g}$, the error is 1.9\%; Explosion pressure TBD620V16 15.55 MPa, TBD620 single-cylinder engine has a value of $15.15 \mathrm{MPa}$, the error is $2.6 \%$, single cylinder with 16 cylinder machine test error of measured data in the range of allowable error, prove the design and build 620 single-cylinder engine test-bed is correct, can be used for the follow-up test.

Table 4.2Comparison of test data and test data of TBD620V16 TBD620 single cylinder diesel engine.

\begin{tabular}{ccccc} 
& $\begin{array}{c}\text { power } \\
(\mathrm{kW})\end{array}$ & $\begin{array}{c}\text { Fuel } \\
\text { consumption } \\
\text { rate }(\mathrm{g} / \mathrm{kWh})\end{array}$ & $\begin{array}{c}\text { Detonation } \\
\text { pressure } \\
(\mathrm{MPa})\end{array}$ & $\begin{array}{c}\text { Average effective } \\
\text { pressure } \\
(\mathrm{MPa})\end{array}$ \\
\hline TBD620V16 & 160 & 202 & 15.55 & 1.753 \\
$\begin{array}{c}\text { TBD620Single } \\
\text { cylinder machine }\end{array}$ & 160 & 206 & 15.15 & 1.725 \\
\hline
\end{tabular}


TBD620 single-cylinder engine parts precision measurements before and after the experiment, shows that 620 single-cylinder diesel engine developed by the overall structure and reliable in performance, abrasion of parts and components conform to the requirements, the technology is stable, the whole machine reliability meet the requirements. Through bench test of a 620 single cylinder diesel engine technical data, for further improvement of series 620 diesel engines provide reliable technical support.

\section{conclusion}

Based on single cylinder TBD620 machine structure parameters, such as using AVL BOOST software calculation model is established for TBD620 single cylinder diesel engine, the working process of the simulated calculation; This calculation using today's advanced working process simulation analysis software, the working process of the established calculation model and the basic parameters selected in accordance with the actual situation of TBD620 single cylinder diesel engine.Using simulated data, and done before TBD620V16 test data for comparative analysis, right after the verification model, through the AVL BOOST software to performance analysis of 620 single cylinder machine.For TBD620 single-cylinder machine boot operation, stable operation without exception, test-bed is set is proved to be reasonable. Performance test, record the data, and with previously done TBD620V16 comparing test data validation. The test result error is smaller.

\section{References}

[1] Liu Xueyuan. Simulation and Experimental Research on lubrication system of D30 diesel engine [D]. Kunming University of Science and Technology, 2007

[2] McMillian M H, Gautam M. Combustion and emission characteristics of Fischer-Tropsch and standard diesel fuel in a single-cylinder diesel engine[R].SAE Technical Paper, 2001.

[3] Ma Chengcheng. Design and low temperature test research of SCR diesel engine low temperature thawing test bench [D]. Shandong University, 2013 